\title{
New Air-Launched Small Missile (ALSM) Flight Testbed for Hypersonic Systems
}

\author{
Trong T. Bui* and David P. Lux ${ }^{\dagger}$ \\ NASA Dryden Flight Research Center, Edwards, California, 93523 \\ Michael T. Stenger and Michael J. Munson ${ }^{\S}$ \\ Naval Air Warfare Center, Weapons Division, China Lake, California, 93555 \\ and \\ George F. Teate \\ Science Applications International Corporation (SAIC), Edwards, California, 93523
}

\begin{abstract}
A new testbed for hypersonic flight research is proposed. Known as the Phoenix air-launched small missile (ALSM) flight testbed, it was conceived to help address the lack of quick-turnaround and cost-effective hypersonic flight research capabilities. The Phoenix ALSM testbed results from utilization of two unique and very capable flight assets: the United States Navy Phoenix AIM-54 long-range, guided air-to-air missile and the NASA Dryden F-15B testbed airplane. The U.S. Navy retirement of the Phoenix AIM-54 missiles from fleet operation has presented an excellent opportunity for converting this valuable flight asset into a new flight testbed. This cost-effective new platform will fill an existing gap in the test and evaluation of current and future hypersonic systems for flight Mach numbers ranging from 3 to 5. Preliminary studies indicate that the Phoenix missile is a highly capable platform. When launched from a high-performance airplane, the guided Phoenix missile can boost research payloads to low hypersonic Mach numbers, enabling flight research in the supersonic-to-hypersonic transitional flight envelope. Experience gained from developing and operating the Phoenix ALSM testbed will be valuable for the development and operation of future higher-performance ALSM flight testbeds as well as responsive microsatellite-small-payload air-launched space boosters.
\end{abstract}

\section{Nomenclature}

$\begin{array}{ll}\text { ALSM } & =\text { air-launched small missile } \\ \text { ASAT } & =\text { air-launched anti-satellite } \\ \text { FTS } & =\text { flight termination system } \\ \text { T\&E } & =\text { test and evaluation }\end{array}$

\section{Background}

Uurrent and future hypersonic systems can benefit greatly from improved test and evaluation (T\&E) capabilities
in flight. While tremendous improvements in modeling and simulation as well as ground-test capabilities have
produced a wide range of new hypersonic concepts, the lack of quick-turnaround hypersonic T\&E capabilities in
flight has hindered the development of these concepts into new hypersonic flight vehicles.
The Phoenix Air-Launched Small Missile (ALSM) platform was conceived to help address the lack of quick-
turnaround and cost-effective hypersonic flight research capabilities. The Phoenix ALSM platform results from a

* Aerospace Engineer, Propulsion and Performance, MS 4840B, P.O. Box 273, AIAA Senior Member.

${ }^{\dagger}$ Branch Chief, Propulsion and Performance, MS 4840B, P.O. Box 273.

* Computer Scientist, Code 47J120D, 1900 N. Knox Rd., Stop 6604.

${ }^{\S}$ Weapons Airframe Technology Manager, Code 476000D, 1900 N. Knox Rd., Stop 6622, AIAA member.

" Senior Systems Analyst, MS 4830C, P.O. Box 273. 
cost-effective utilization of two unique and very capable flight assets: the United States Navy Phoenix AIM-54 longrange, guided air-to-air missile and the NASA F-15B flight research airplane.

Figure 1 shows a standard Phoenix AIM-54 missile. It is a long-range, guided air-to-air missile designed to be carried by the U.S. Navy F-14 Tomcat airplane. The Phoenix missile has a length of $13 \mathrm{ft}$, a diameter of $15 \mathrm{in}$, and a wingspan of $3 \mathrm{ft}$. The total weight of a standard Phoenix missile is $1024 \mathrm{lb}$, including a 135-lb warhead. Designed to intercept air targets at a range in excess of $100 \mathrm{nmi}$, the Phoenix missile consists of a guidance section, armament section, propulsion section, control section, interconnecting surface cables, wings, and fins. The missile is ejectionlaunched from the F-14 airplane. Semi-active and active homing radar and hydraulically-operated fins direct and stabilize the missile on course to the target. Propulsion is provided by a solid-propellant rocket motor. Although it is a large missile, the Phoenix missile is both significantly smaller and lighter than the air-launched anti-satellite (ASAT) missile, successfully launched from a United States Air Force F-15A airplane in 1984 at Edwards Air Force Base, Edwards, California.

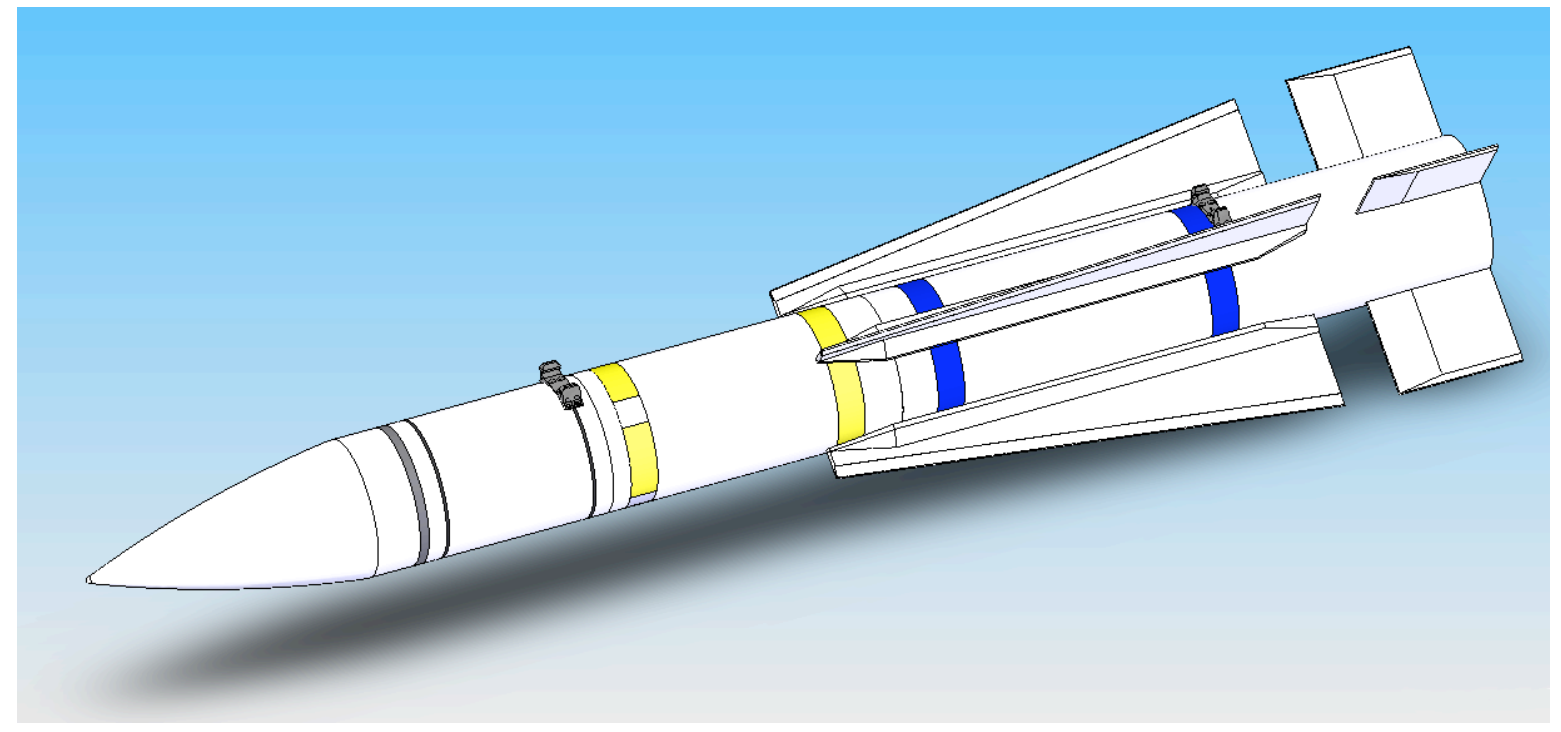

Figure 1. The AIM-54 Phoenix guided air-to-air missile.

In the proposed Phoenix ALSM test platform, the modified Phoenix missile is used as a high-supersonic-lowhypersonic, precision-guided booster for flight research experiments. When the missile's radar seeker, attendant signal processing equipment, target detector, and warhead are removed, it is possible to have a research payload volume of more than $7 \mathrm{ft}^{3}$ and an allowable weight of up to $250 \mathrm{lb}$. Additionally, the performance of the standard Phoenix missile can be significantly increased by launching it from a high-performance carrier airplane such as the NASA F-15B airplane.

The NASA F-15B research airplane is a modified F-15B jet fighter airplane that has been providing NASA, the Department of Defense, private industry, and universities a long-term capability for flight research in the areas of aerodynamics, instrumentation, propulsion, materials, and structures. A unique and versatile airborne resource, the NASA F-15B airplane enables flight research of a wide variety of aerospace technologies through either the Flight Test Fixture ${ }^{1}$ or the Propulsion Flight Test Fixture $^{2}$ mounted underneath, on the airplane centerline. Recent experiments that have been flown on the NASA F-15B airplane include the Aerostructures Test Wing, the Shuttle External Tank Insulation Test, and Durability of Thermal Protection System (TPS) materials for Reusable Launch Vehicles (RLV). Several different flight experiments are typically flown on the NASA F-15B airplane each year, making it a highly productive flight research testbed.

Figure 2 is a computer-enhanced photograph of the proposed Phoenix ALSM platform during a launch. The Phoenix missile system will be modified and mounted on the centerline station of the NASA F-15B airplane. In this configuration, the modified Phoenix missile, or ALSM, becomes in effect a hypersonic wind tunnel sting in the sky. Many different types of hypersonic research payloads, including scramjet subscale models or individual scramjet components such as inlets, isolators, and combustors, can be mounted in front of the ALSM, shrouded by a frangible nose cone that duplicates the outer mold line (OML) of the baseline Phoenix missile. When the ALSM reaches the 
desired test condition, the radome shroud can be separated from the front end of the missile, exposing the research payload to the incoming freestream flow. The ALSM test platform will be guidance-controlled by an integrated IBM PowerPC ${ }^{\circledR}$ (International Business Machines, Armonk, New York) computer and autopilot system and be fitted with a configurable, high-fidelity, wideband telemetry and flight termination system (FTS) for flight-test data collection. The ALSM test platform can be programmed to provide static flight conditions as well as transient, maneuvering flight conditions for the experiment. As well, it can be programmed to follow a certain flight trajectory, such as a rocket-based combined cycle (RBCC) or a turbine-based combined cycle (TBCC) vehicle ascend trajectory to evaluate the performance of the research payload in a relevant flight environment. For tests such as autonomous FTSs for hypersonic flight vehicles, the ALSM itself can function as the research demonstration vehicle for design research and proof of concept.

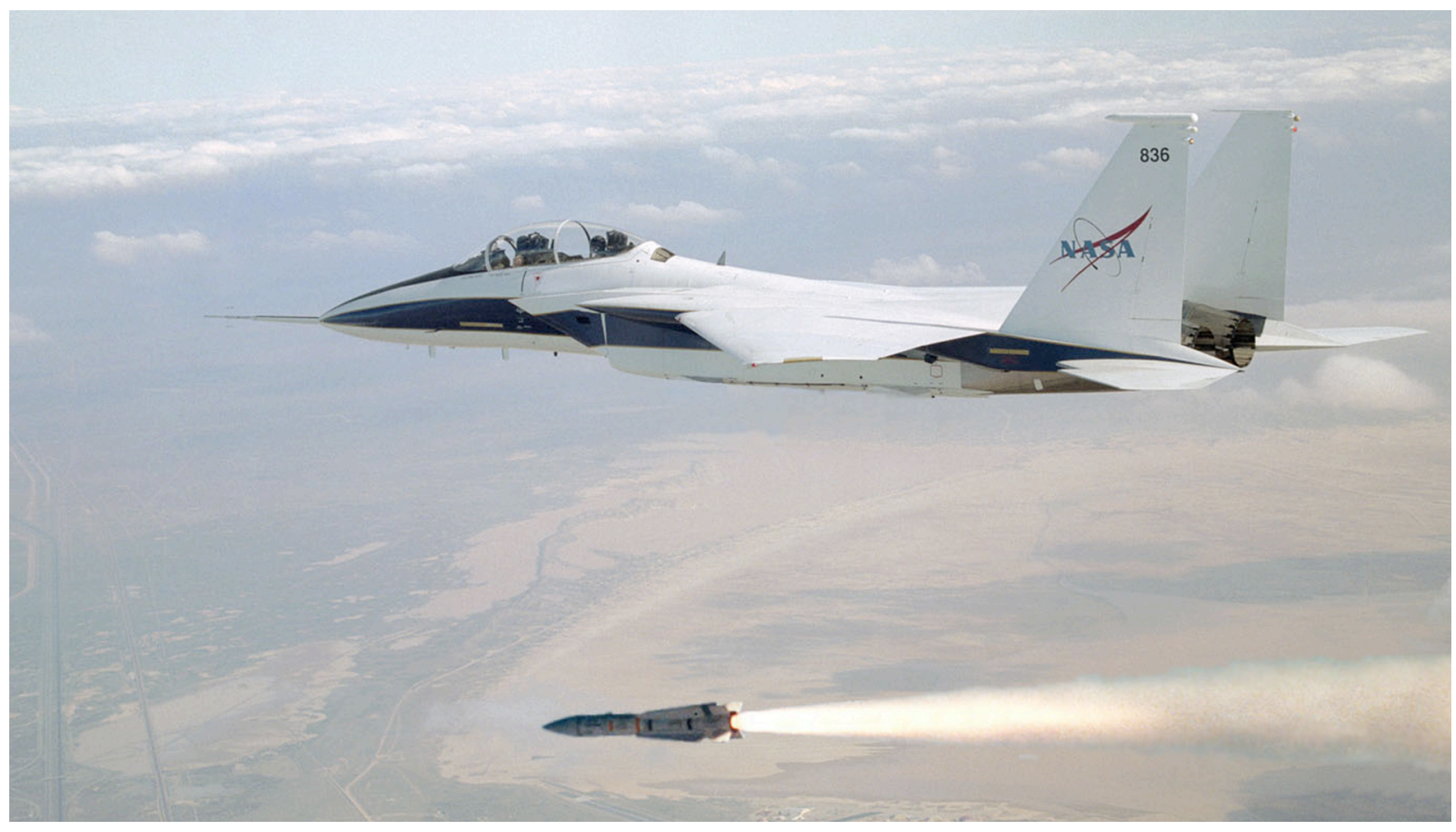

Figure 2. Computer-enhanced photograph of the proposed ALSM hypersonic test and evaluation platform.

The experience gained from developing and operating the Phoenix ALSM hypersonic T\&E capability will provide a cost-effective stepping stone for the development and operation of more advanced, higher-performance ALSM hypersonic flight testbeds as well as responsive microsatellite-small-payload air-launched space boosters in the future.

\section{Benefits of the Air-Launched Small Missile Test Platform}

Rapid progress in aerospace technologies requires a constant interplay between analysis, ground-testing, and flight-testing activities. All three of these activities are equally important. Testing, both on the ground and in flight, keeps analysis well-grounded and relevant, while analysis provides the foundation and explains flight- and groundtest results. Often, the sparks of insight gleaned from one of these activities greatly benefits the other two, if all three activities are done in concert, accelerating the maturation of advanced aerospace technologies.

The proposed ALSM test platform will assist in taking advanced hypersonic concepts to flight quickly. Hundreds of AIM-54 Phoenix missiles were excessed by the military during the government fiscal year 2004 and have entered the de-militarization process by which these highly capable assets will be destroyed. We propose that a selected number of these Phoenix missiles be modified and used as the low-cost ALSM hypersonic T\&E flight-test platform, leveraging the extensive operational experience and resources that the U.S. Navy has already developed for the Phoenix missile. 
The Phoenix ALSM platform can fill a gap in hypersonic flight T\&E capabilities. Figure 3 shows capabilities in flight that are presently available. The NASA Dryden F-15B airplane testbed offers a flight research capability up to Mach 2. Current hypersonic flight research capabilities such as the X-43 $\mathrm{A}^{3}$ and HyShot concentrated only on the hypersonic flight vehicle cruise Mach numbers of 7 and above. The Central Institute of Aviation Motors (CIAM), (Moscow, Russia) scramjet flight test ${ }^{5}$ reached a maximum flight Mach number of approximately 6.5. With the retirement of the NASA Dryden SR-71 airplane as a high-speed flight testbed, there is currently no flight testresearch capability at Mach 3. It can be seen from Fig. 3 that there is a gap in flight-test capability in the Mach number range of 2 to 5 . The proposed ALSM platform can fill this important gap in current flight-test capabilities well.

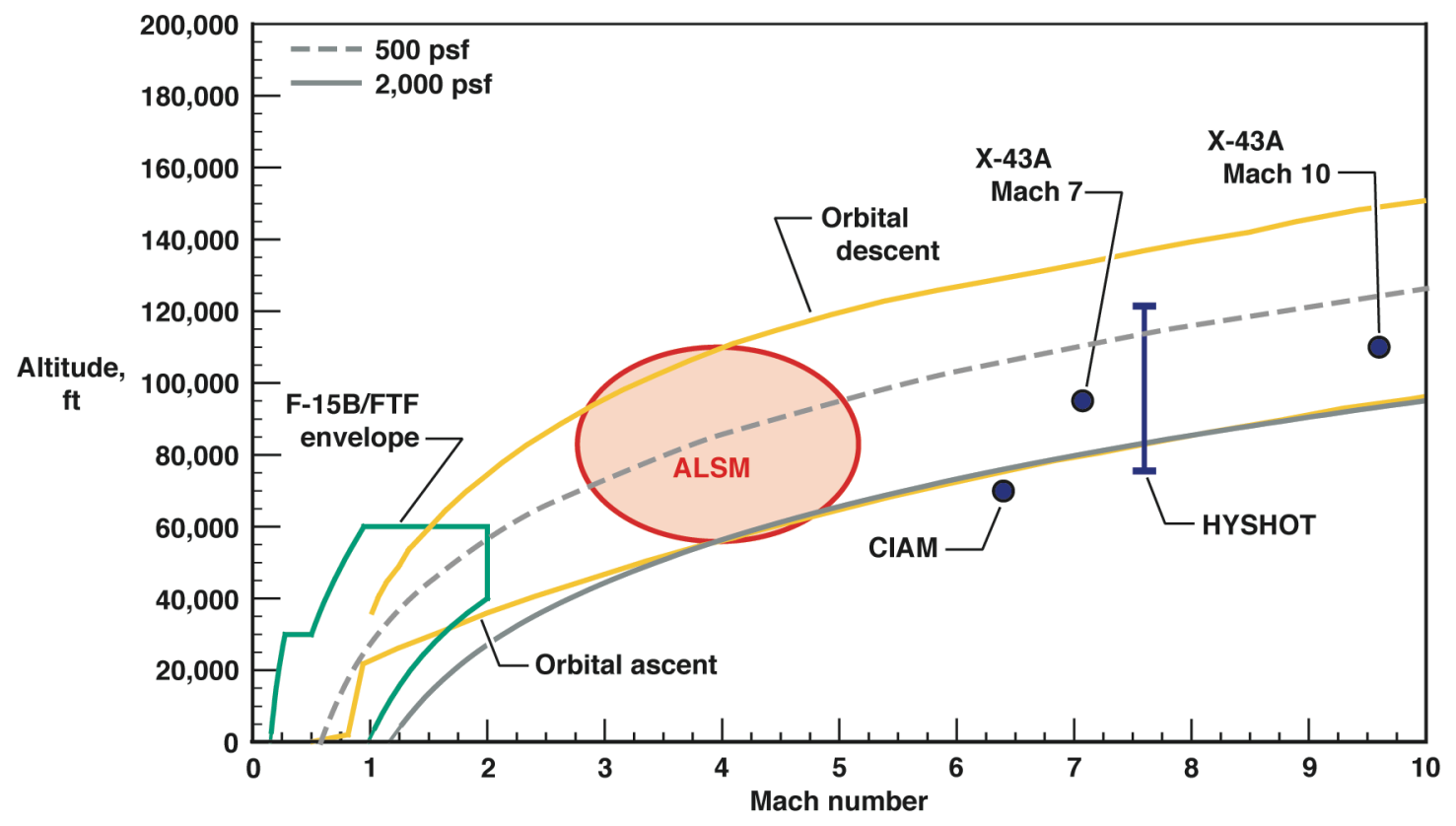

Figure 3. The ALSM can fill an important gap in current flight test and evaluation capabilities.

The range of flight-test conditions that the proposed ALSM system can provide is important for the development of hypersonic systems. As can be seen in Fig. 4, most known hypersonic propulsion systems require an accelerator, such as a turbojet or a rocket, to provide the boost to the high-supersonic Mach number range of 3 to 4 , before transitioning to ramjet or other modes of hypersonic flight operation. In addition, with the dual-mode scramjets and the dual-combustion ramjet (DCR), the transition of ramjet-to-scramjet operation takes place in the range of Mach 4 to Mach 6. During these critical transitional flight regimes, the performance and operability of the scramjet are significantly affected by the inlet flow physics, precombustion shock system location, combustor design, and fueling. More importantly, vehicle acceleration through ramjet-to-scramjet transition has not yet been demonstrated in flight. 


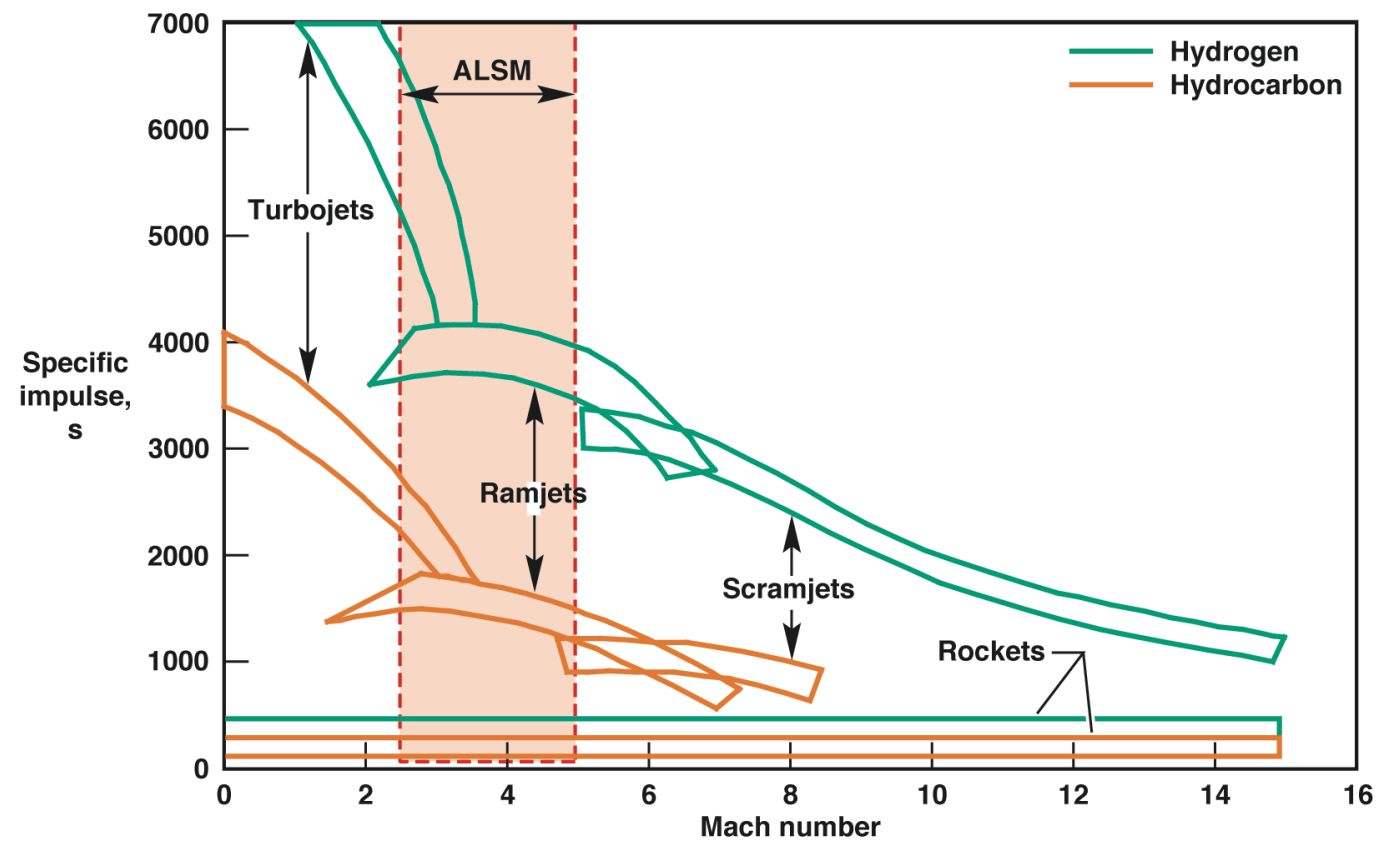

Figure 4. The ALSM enables test and evaluation of hypersonic systems in the Mach 3 to Mach 5 range.

In addition to hypersonic airbreathing propulsion, the ALSM test platform will enable high-speed flight research of other important aerospace research topics such as high-speed laminar-turbulent transition, heat transfer, wave rider shapes, TPS material and ablative treatments, as well as advanced flight instrumentation, flight sensors, and telemetry system development. The ALSM will also be valuable for the development and evaluation of new highspeed flight maneuvers and technologies for aero-capture-aero-assist, autonomous-adaptive mission management, and re-entry-decelerator concepts that are important to the national space exploration goals.

The ALSM test platform can support planned hypersonic systems for defense applications such as the Defense Advance Research Projects Agency (DARPA) and the U.S. Air Force's Force Application and Launch from CONtinental United States (FALCON) program, the Responsive Access, Small Cargo, Affordable Launch (RASCAL) program, and the U.S. Navy Revolutionary Approach To Time Critical Long Range Strike (RATTLRS) program. The ALSM test platform provides the opportunity to test scale inlets under actual flight conditions for inlet operability and performance data. Ground-to-flight correlations from comparing ground-test data to flight-test data for these inlets will improve and validate inlet computational fluid dynamics (CFD) analysis-design codes. Highspeed store separation flight data obtained from ALSM flight tests can improve and validate modeling and simulation codes for store separation, supporting the FALCON program for separation of the Common Aero Vehicle (CAV) from the FALCON Hypersonic Cruise Vehicle (HCV). Testing of an autonomous FTS such as the Subminiature Flight Safety System using the ALSM would support the DARPA and U.S. Air Force FALCON CAV flight test from the FALCON Space Launch Vehicle (SLV), the U.S. Navy RATTLRS, and the U.S. Air Force Advanced Responsive Space Lift (ARES) programs by providing the option of an autonomous FTS that has been previously verified by flight-test demonstrations on the ALSM test platform.

\section{Markets for the Air-Launched Small Missile Capabilities}

Markets for this new hypersonic flight-test platform would include NASA, the Department of Defense, the private aerospace industry, private research laboratories, and university research organizations. Experience gained through developing and operating this new platform would be valuable for future space launch business in the area of on-demand, responsive microsatellite-small-payload space-launch services. The needs presently exist for a costeffective, quick-turnaround hypersonic flight-test capability as well as on-demand, responsive microsatellite space launch services, and these needs will likely become more pressing in the future. 
The marketing niche that this new test platform would fill is shown in Table 1 below. There is currently no quick-turnaround, low-cost, guided hypersonic flight-test capability available in the Mach number range of 3 to 5 . A comparison of flight-test capabilities is also given in this table. Both the NASA F-15B airplane and the HyShot sounding rocket approaches utilize assets that have already been developed, and there is no development cost for these platforms. It is anticipated that once developed, the ALSM platform will have launch costs that are similar to the NASA F-15B airplane and the sounding rocket approaches. There was a significant development cost for the $\mathrm{X}-43 \mathrm{~A} /$ Pegasus ${ }^{\circledR}$ (Pegasus is a registered trademark of Orbital Sciences Corporation, Dulles, Virginia) platform, and the cost per launch was very high. Therefore, it is not feasible to use the X-43A vehicle routinely as a platform for T\&E. The retirement of the NASA B-52B airplane as a carrier airplane without a replacement will also make it difficult to restart the X-43A test capabilities in the future.

Table 1. Comparison of current hypersonic flight-test capabilities.

\begin{tabular}{|c|c|c|c|c|}
\hline $\begin{array}{c}\text { Flight test and } \\
\text { evaluation } \\
\text { capability } \\
\end{array}$ & $\begin{array}{c}\text { Mach number } \\
\text { range }\end{array}$ & $\begin{array}{c}\text { Relative cost } \\
\text { magnitude }\end{array}$ & Guided? & $\begin{array}{c}\text { Quick- } \\
\text { turnaround } \\
\text { operation? }\end{array}$ \\
\hline $\begin{array}{l}\text { NASA F-15B } \\
\text { airplane }\end{array}$ & $<2$ & Low & Yes & Yes \\
\hline $\begin{array}{l}\text { HyShot-sounding } \\
\text { rockets }\end{array}$ & $>7$ & Low & No & Yes \\
\hline X-43A/Pegasus & $>7$ & High & Yes & No \\
\hline Phoenix ALSM & 3 to 5 & Low & Yes & Yes \\
\hline
\end{tabular}

\section{Proposed Deliverables}

A comprehensive approach is planned for the proposed development effort. Analysis as well as flight testing will be conducted in a complementary and integrated manner, leading to actual flight demonstrations of the ALSM testbed. During the initial or envelope-expansion flights, actual hypersonic flight research payloads such as highspeed laminar-turbulent transition, hypersonic inlet, or TPS material flight research experiments could also be flown, obtaining valuable high-speed flight data for comparison with ground-test data and analysis results.

The proposed deliverables for this effort will include:

1. ALSM system description and design documentation

a. Guidance and control system architecture

b. Interface definitions

c. Modeling and simulation

d. Telemetry description and capabilities

e. Certified FTS

f. Range safety package for flight-test events at Naval Air Warfare Center, Weapons Division (NAWC-WD) test ranges

2. F-15 airplane integration

a. ALSM/F-15 interface definitions

b. Airplane store separation analysis

c. Flight-test methodology reports and analysis

d. U.S. Air Force SEEK EAGLE Office (AFSEO) flight clearance

3. Demonstration of actual ALSM launches

a. ALSM initial proof-of-concept demonstration

i. Stores separation

ii. Guidance and control authority demonstration

iii. Test objective and envelope capability

iv. FTS demonstration

b. ALSM envelope expansion demonstrations

i. Unique payload integrations and test

ii. System utility

iii. Correlation data 
4. Modification data package for converting de-militarized AIM-54 assets to ALSM test platforms

5. System safety, design, and test reports.

\section{Preliminary Schedule and Milestones}

A preliminary schedule and associated milestones have been created for the proposed effort. The proposed schedule and milestones could be modified based on available funding and resources. During the first year, preliminary design for the ALSM platform will be conducted. Considerations such as ALSM/F-15 interface design, F-15 airplane modification and integration, ALSM guidance system, ALSM telemetry or FTS systems, airplane flight envelope, airplane-ALSM separation, and flight clearance will be studied. Detailed system design together with hardware fabrication and modification will be conducted during the second and third year. Captive-carry flight clearance, envelope expansion, and ALSM initial proof of concept flight demonstrations will be conducted during the later half of the third year with test ALSM missile rounds. It is anticipated that at least two ALSM research flights with actual flight experiments on board will be conducted during the fourth year to demonstrate the capability of the ALSM as a hypersonic testbed.

Table 2. Preliminary schedule and milestones.

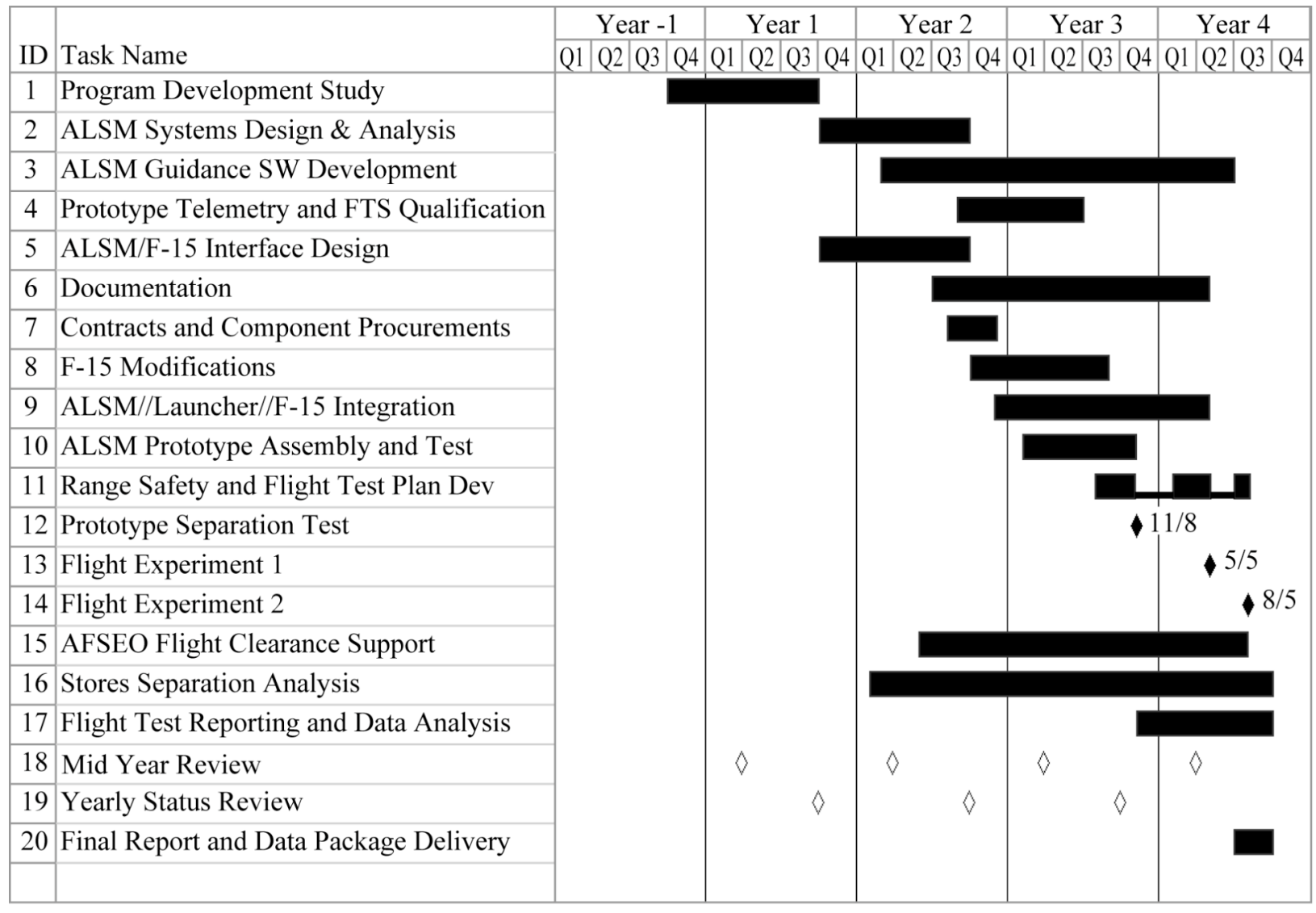




\section{Technical Rationale, Approach, and Plan}

Currently, there is no cost-effective means of collecting dynamic flight-test data for hypersonic test articles without accepting the limitations involved with the use of unguided sounding rockets at one end of the spectrum, or the long development cycle and large costs associated with X-plane programs on the other end of the spectrum.

Figure 5 illustrates the ALSM platform concept. We propose that modified Phoenix missiles, or ALSM test platforms, are a cost-effective and pragmatic solution that will address the needs of the hypersonic development and test community for the next 10 to 15 years, filling the gap between the unguided sounding rocket and X-plane test platforms. The ALSM test platform will have the Phoenix missile radar seeker, attendant signal processing, target detector, and warhead removed to provide an estimated payload volume of more than $7 \mathrm{ft}^{3}$ and an allowable weight of up to $250 \mathrm{lb}$. This payload capacity could be used for mounting unique flight-test articles such as subscale scramjet models, or individual scramjet components such as inlets, isolators, and combustors that will be shrouded within the OML of the baseline Phoenix. Upon reaching the desired test conditions, the ALSM radome shroud will be separated from the vehicle, exposing the payload to freestream flows.

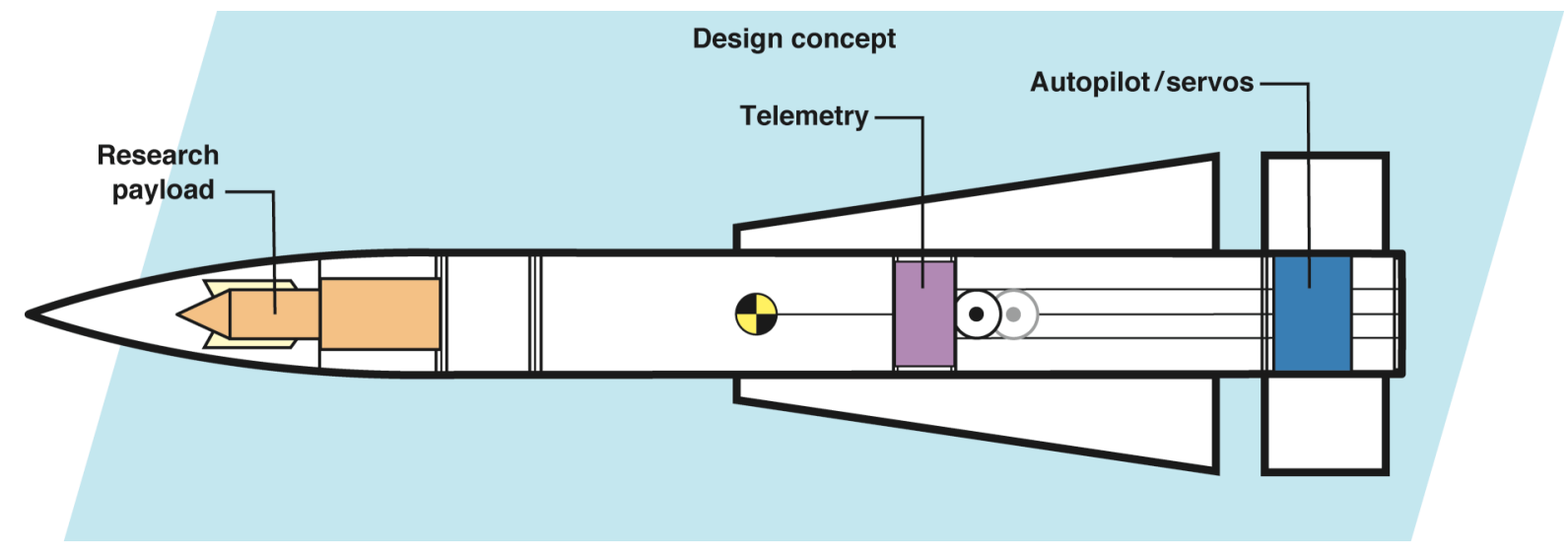

Figure 5. Phoenix ALSM test platform concept.

Given the baseline performance of the Phoenix missile, the extended range capability, ALSM guidance controls, and the ability to precisely control initial launch conditions using the NASA F-15B airplane, the ALSM test platform will provide economical test repeatability and flexibility in the test envelope between Mach 3 and Mach 5 .

Figure 6 illustrates the operational model for the ALSM test platform. The ALSM test platform will be carried by the NASA F-15B airplane on its centerline store station, similar to the U.S. Air Force ASAT configuration. It will then be air-launched from the F-15B airplane over the Pacific Missile Test Center (PMTC), Point Mugu, California, similar to the $\mathrm{X}-43 \mathrm{~A}$ flight experiments. 


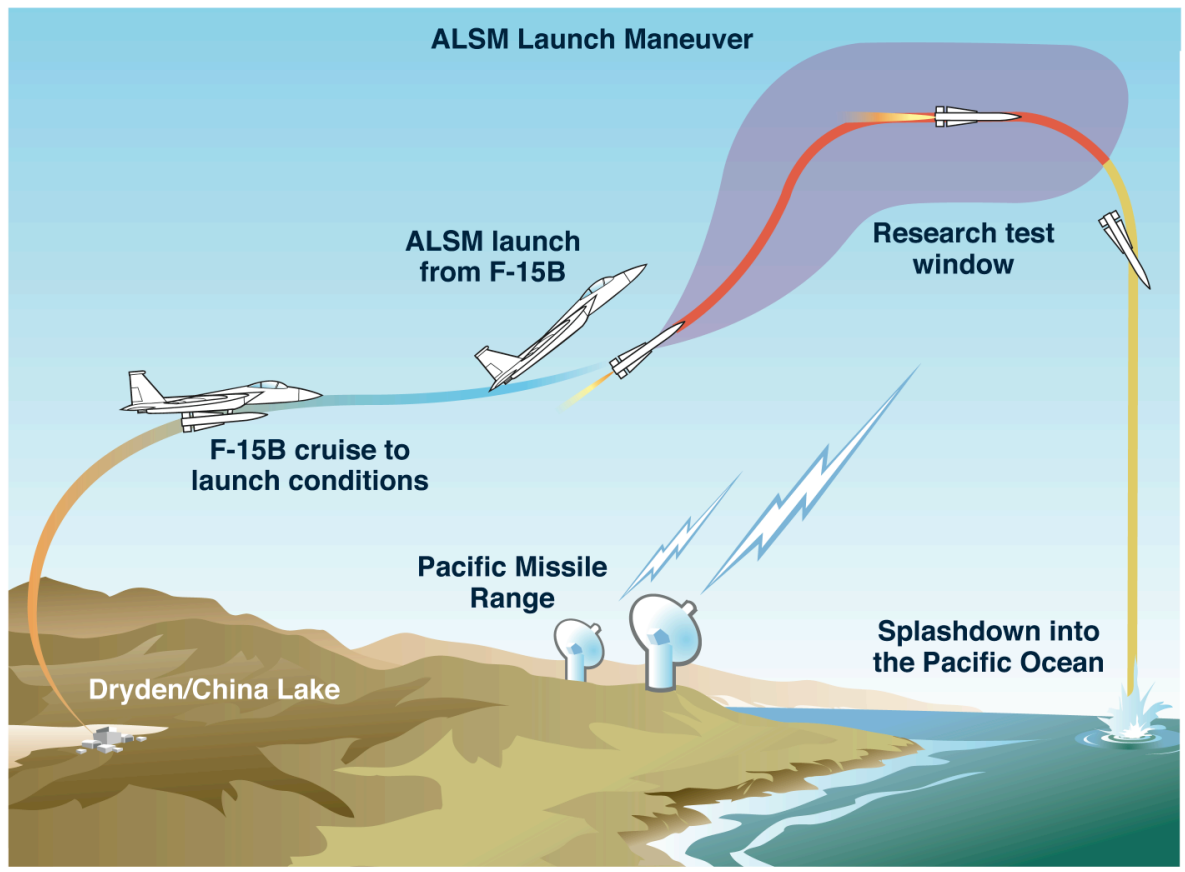

Figure 6. Operational model for the Phoenix ALSM test platform.

The ALSM test platform will be guidance-controlled by an integrated PowerPC computer, autopilot, and inertial measurement unit (IMU) system. Initial prototype development and demonstration are anticipated to include "preprogrammed" maneuver capability, but the design shall include the ability to integrate global positioning system (GPS) updates and "route following" capability to address problems associated with high-speed, low altitude article dispense test utility.

Data collection will be accomplished by a configurable, high-fidelity, wideband telemetry (TM) system. The TM system will be developed to include an integrated FTS to meet standard range safety requirements. Telemetry data will be collected onsite at the PMTC sea range and sent real-time to the NASA range operations facility by way of microwave link as demonstrated by numerous collaborative test ventures with both NASA and the Air Force at the Air Force Flight Test Center (AFFTC), Edwards, California.

Separable radome development will incorporate expanding explosive materials embedded in channels along the radome assembly. During flight test, the guidance computer will initiate the explosive train, separating the dome from the ALSM platform and exposing the payload to freestream air.

The NASA F-15B airplane has an extensive history of flying with unique and configurable flight-test articles, ranging from space shuttle tiles to the supersonic laminar wing. As a result, the experimental instrumentation system and carriage hardware of the NASA F-15B airplane are highly adaptable and especially suited to unique flightresearch payloads such as the ALSM. Modifications to the NASA F-15B airplane for ALSM experiments will leverage the experience that has been gained through the years from flying a wide variety of F-15B airplane flight research experiments at the NASA Dryden Flight Research Center.

It is anticipated that test events will be performed at the PMTC, with the airplane staging from either NASA Dryden or from one of the NAWC-WD facilities, depending upon which facility is most cost-effective to the program.

\section{Preliminary Performance Analysis}

Preliminary performance analysis for the proposed ALSM test platform has been conducted using publicly available data on the Phoenix missile and a simple in-house trajectory analysis code at NASA Dryden. Zero-lift trajectories were considered with no missile guidance (fixed fins). Missile performance sensitivities to launch elevation angles, launch Mach numbers, and research payload weights are shown to illustrate potential performance trends of the ALSM test platform. Because of possible inaccuracies in the publicly available data for the Phoenix 
missile, higher-fidelity performance analyses should be conducted to determine the suitability of the ALSM test platform prior to actual hypersonic flight research experiments. In particular, the guidance capability of the ALSM should be used to optimize the missile trajectory in reaching the required test conditions.

As an air-launched flight-test platform, the proposed ALSM test platform has several advantages. Hazardous or high-risk flight tests could be conducted on an autonomous missile booster at great distances from the carrier airplane. The high-performance NASA F-15B airplane can boost the performance and enlarge the flight envelope of the Phoenix missile booster. Also, the launch altitude, attitude, and location are flexible. Finally, the research payload can be checked-out in the captive-carry flight environment at altitudes so that operation of the research instrumentation and data telemetry systems could be verified before the actual launch.

Unless noted otherwise, the standard Phoenix missile and warhead weights were used in these simulations. The launch elevation angle effects on the ALSM performance are shown in Fig. 7. It can be seen that increasing the launch elevation angle from 0 deg to 30 deg significantly increases the maximum Mach number and range of the missile. Increasing the launch elevation angle from $30 \mathrm{deg}$ to $45 \mathrm{deg}$ results in a very small loss in maximum Mach number, but greatly increases flight time. For example, launching the Phoenix missile at 45 deg produces over $100 \mathrm{~s}$ of flight speeds above Mach 3. It should be noted that even larger launch angles were used in previous flight tests. In the 1960 s, sounding rockets were launched from the NASA F-104 airplane at near-vertical airplane pitch attitudes. ${ }^{6}$

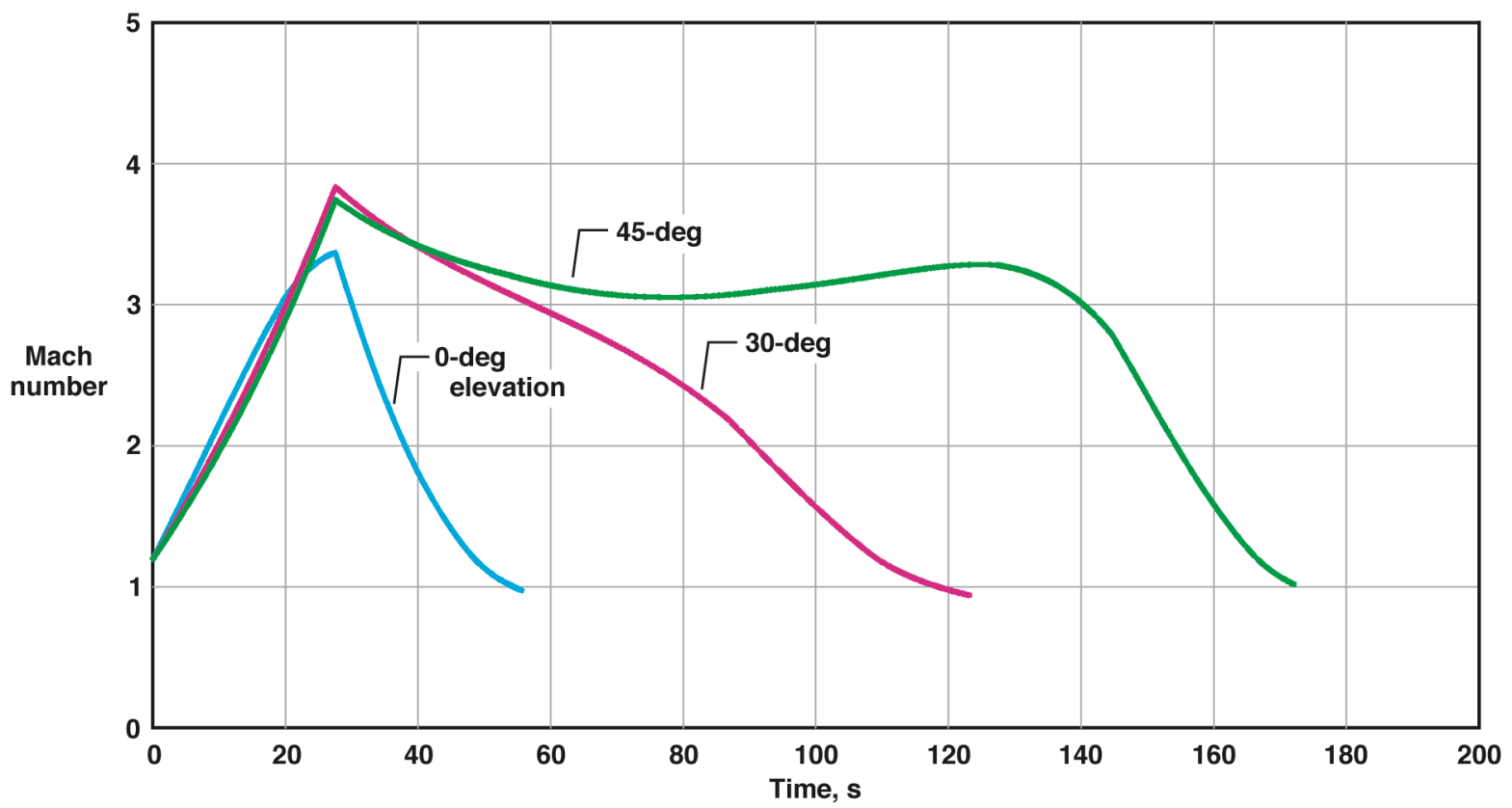

Figure 7. Launch elevation angle effects on ALSM flight performance (Mach 1.2, 45,000-ft launch conditions).

The effects of initial launch velocity are shown in Fig. 8. It can be seen that any increase in the initial launch Mach number results in a corresponding direct increase in the maximum Mach number of the missile as well as in missile flight time. With neither missile guidance nor trajectory optimization, maximum missile Mach numbers approaching 4 are achievable with a supersonic launch speed of Mach 1.2. 


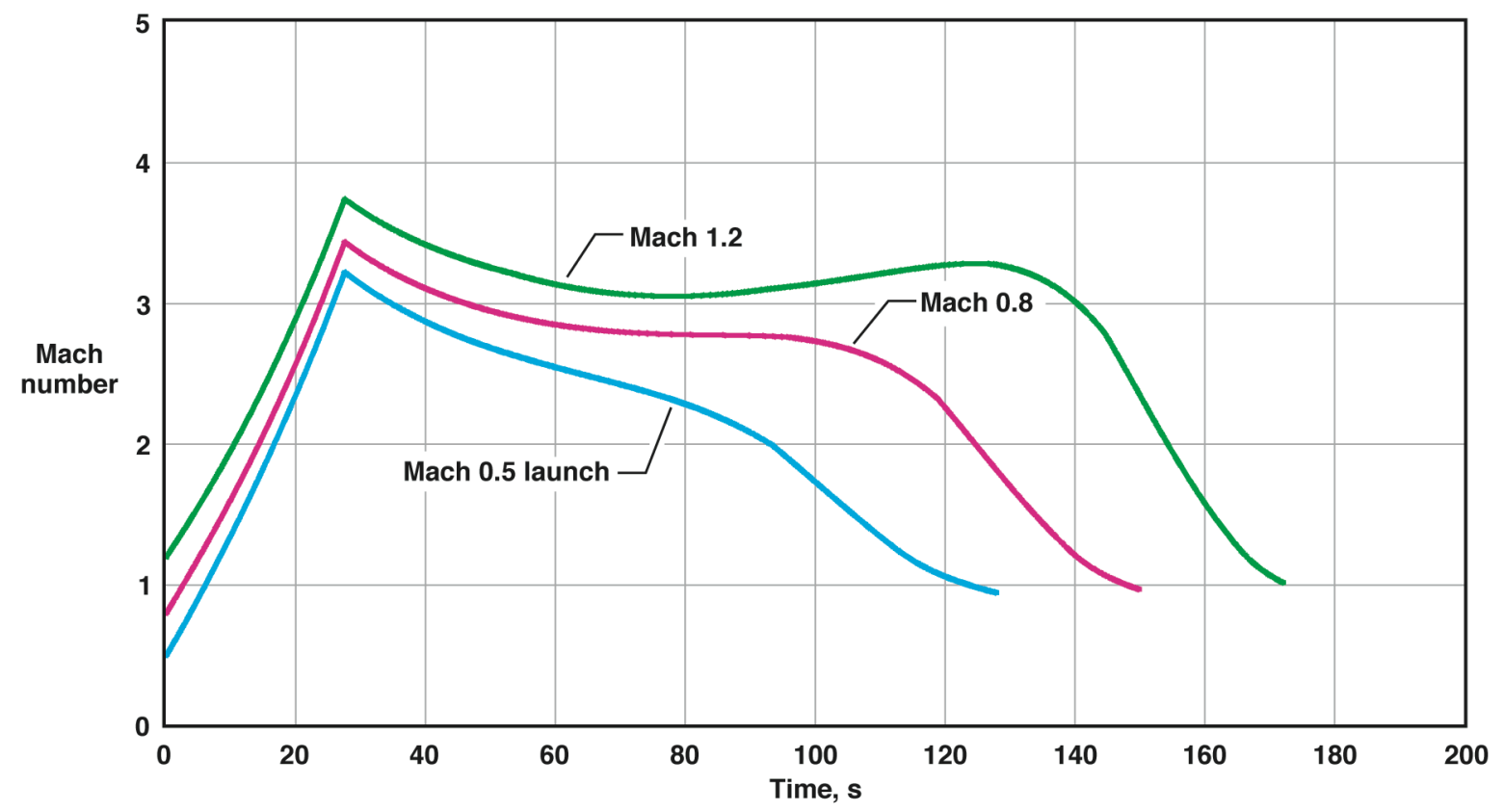

Figure 8. Initial launch Mach number effects on ALSM flight performance (45-deg elevation angle, $45,000-f t$ launch conditions).

Figure 9 shows that reducing weight will significantly increase missile performance. When the Phoenix missile's radar seeker, attendant signal processing equipment, target detector, and warhead are removed, it is possible to have an allowable research payload weight of up to $250 \mathrm{lb}$. As can be seen in Fig. 9, an 85-1b weight reduction from the standard missile weight (allowable research payload weight of $165 \mathrm{lb}$ ) increases the top missile Mach number to slightly above 4.0 and increases the missile flight time. Reducing the missile weight by $135 \mathrm{lb}$ (allowable research payload weight of $115 \mathrm{lb}$ ) increases the maximum missile Mach number to 4.3. Finally, reducing the missile weight by the full $250 \mathrm{lb}$ allows a top missile Mach number of 5.0. It should be noted that to keep costs low, the Phoenix missile weight cannot be changed arbitrarily. The center of gravity (CG) and center of pressure (CP) of the ALSM should agree with those of the standard Phoenix missile to within acceptable tolerances to minimize airplane store separation and flight clearance costs. ALSM tests with drastically different mass properties and OMLs from the standard Phoenix missile will likely cause an increase in flight clearance costs. 


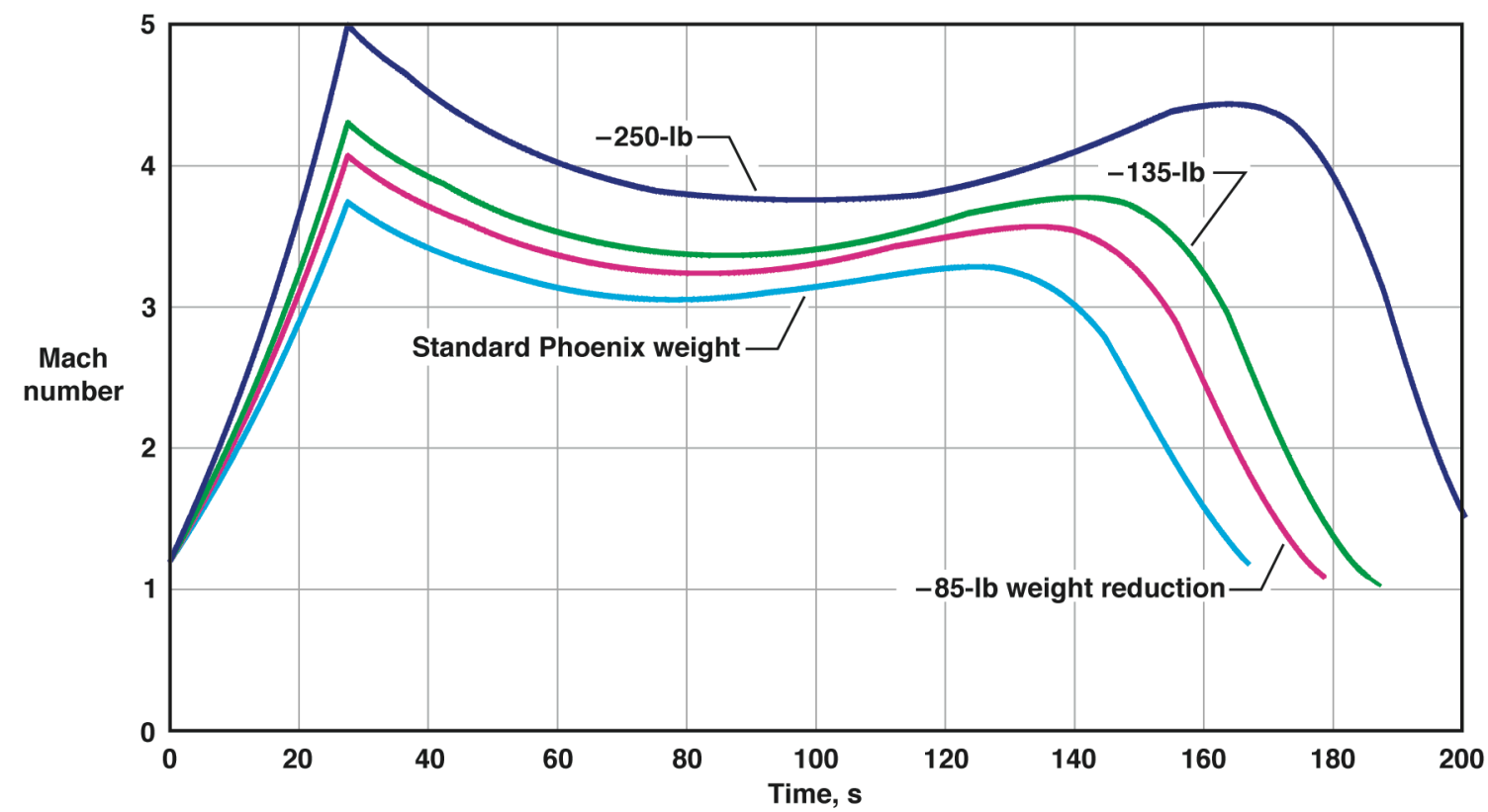

Figure 9. Missile weight effects on ALSM flight performance (Mach 1.2, 45-deg elevation angle, 45,000-ft launch conditions).

\section{Related Hypersonic Flight-Test Capabilities}

\section{A. X-43A Scramjet Flight Research}

An overview of this very important hypersonic flight research project is provided in Ref. 3. The NASA Dryden Flight Research Center, in partnership with the NASA Langley Research Center and private industry partners, successfully flew the X-43A vehicle at Mach 7 and Mach 10, setting new speed records for airbreathing propulsion aircraft on both flights. A tremendous amount of in-house experience and capability in hypersonic flight research has been developed at NASA Dryden as the result of this flight research effort. The development costs and the launch costs for the X-43A/Pegasus system are very high, however, and this system is not well-suited for quickturnaround and frequent T\&E activities. The retirement of the NASA B-52B as a carrier airplane without a replacement will also make it difficult to restart the X-43A test capabilities in the future. On the other hand, the proposed ALSM platform is designed to provide cost-effective, quick-turnaround hypersonic flight T\&E activities for the Mach number range of 3 to 5 .

\section{B. HyShot-Sounding Rocket Test}

HyShot was a supersonic combustion flight experiment conducted by the University of Queensland, Australia, using a ground-launched sounding rocket. The rocket was unguided, and it targeted test Mach numbers greater than Mach 7. Reference 4 provides a comparison between flight data and analysis results. As a ground-launched platform, it did not have the flexibility that an air-launched asset such as the ALSM could provide in terms of launch locations, altitudes, speeds, and attitudes. As an unguided rocket, it also did not have as much control and flexibility as the guided ALSM platform could provide.

\section{Air-Launched Anti-Satellite Missile}

In the 1980s, the U.S. Air Force conducted flight tests for the ASAT missile system using the F-15A airplane as the launch airplane. This highly successful test program resulted in a first-ever intercept and destruction of a satellite in orbit. The ASAT missile had a length of $18 \mathrm{ft}$ and weighed $2700 \mathrm{lb}$. It was significantly larger and heavier than the proposed Phoenix ALSM system. The mode of operation in this program is virtually identical to the proposed ALSM testbed. Therefore, the success of the ASAT program highlights the excellent feasibility of the proposed ALSM testbed. 


\section{Air-Launched Sounding Rocket}

In the 1960s, the air-launched sounding rocket (ALSOR) research program used a NASA F-104 airplane to launch sounding rockets. The operation of the program is described in detail in Ref. 6. Launch maneuvers and aircraft launchers were developed, and the entire concept of air-launched sounding rockets proved to be practical. Five successful launches were conducted at launch Mach numbers ranging from 0.76 to 1.4 and airplane pitch attitudes ranging from $41 \mathrm{deg}$ to $102 \mathrm{deg}$. The air-launched sounding rockets reached a maximum altitude of $383,000 \mathrm{ft}$.

\section{Conclusions}

A proposal has been developed to add a new Mach 3 to Mach 5 hypersonic flight test, evaluation, and research capability to the existing NASA Dryden Flight Research Center F-15B testbed airplane, called the Phoenix AirLaunched Small Missile (ALSM) flight-test platform. Using United States Navy surplus Phoenix long-range, guided air-to-air missiles as boosters for flight research payloads and the NASA F-15B airplane as the launch airplane, the Phoenix ALSM platform was conceived specifically to address the lack of cost-effective hypersonic flight test and evaluation capabilities in the supersonic-to-hypersonic transitional flight envelope.

Preliminary studies have shown this approach to be technically sound. Performance analysis for the proposed ALSM test platform has been conducted using publicly available data and the assumptions of zero-lift trajectories and no missile guidance. With the appropriate payload weights and launch conditions, the Phoenix can boost a flight research payload to flight conditions of Mach 3 to Mach 5.

The experience gained from developing and operating the Phoenix ALSM hypersonic flight testbed will provide a cost-effective stepping stone for the development and operation of future higher-performance ALSM hypersonic flight testbeds as well as responsive microsatellite-small-payload space-launch boosters. The team, comprised of the NASA Dryden Flight Research Center and the Naval Air Warfare Center Weapons Division, brings together the required skills as well as the corporate experience and technology, acquired from decades of hypersonic flight research, missile research, and high-performance aircraft flight-testing, to successfully execute the proposed effort.

\section{References}

${ }^{1}$ Richwine, D. W., "F-15B/Flight Test Fixture II: A Test Bed for Flight Research,” NASA Technical Memorandum 4782, 1996.

${ }^{2}$ Palumbo, N., Moes, T. T., and Vachon, M. J., "Initial Flight Tests of the NASA F-15B Propulsion Flight Test Fixture," NASA/TM-210736, 2002.

${ }^{3}$ Marshall, L. A., Corpening, G. P., and Sherrill, R., "A Chief Engineer's View of the NASA X-43A Scramjet Flight Test," AIAA-2005-3332, May, 2005.

${ }^{4}$ Boyce, R., Gerard, S., and Paull, A., "The HyShot Scramjet Flight Experiment - Flight Data and CFD Calculations Compared," AIAA-2003-7029, December, 2003.

${ }^{5}$ Roudakov, A. S., Vyacheslav, L. S., and Hicks, J. W., "Recent Flight Test Results of the Joint CIAM-NASA Mach 6.5 Scramjet Flight Program," NASA/TP-1998-206548, 1998.

${ }^{6}$ Horton, V. W., and Messing, W. E., "Some Operational Aspects of Using a High-Performance Airplane as a First-Stage Booster for Air-Launching Solid-Fuel Sounding Rockets,” NASA TN D-1279, 1963. 